\title{
Supply Management: A Transaction Cost Economics Framework
}

Reza Mohammady Garfamy*

Abstract:

Transaction Cost Economics (TCE) is an economic theory that provides an analytical framework for investigating the governance structure of contractual relations within a supply chain. The purpose of this paper is to examine existing research in an effort to understand the potential effects of transaction costs on the vertical coordination of a supply chain. The paper arrives at many insights into how supply chains are organized under different governance structures. These insights can certainly be shared via the development and introduction of related propositions. The conceptual typology of contractual relations developed herein can help researchers better understand the scope of both the problems and the opportunities associated with supply management. It will be of value, therefore, not only to researchers who desire to expand their research into this area, but also to those who have already investigated this topic in isolation or with limited scope.

Keywords: Transaction cost economics, TCE, Supply chain, Supply management, vertical coordination.

JEL: D23, L14

DOI: $10.2478 / \mathrm{v} 10033-012-0022-6$

\section{Introduction}

A variety of changes in the business environment, including global competition, international cooperation, and vertical disintegration, along with a focus on core competencies, have fueled interest in networked supply chains (Chen \& Paulraj, 2004). This novel perspective has created the challenge of developing insights into how and why different supply chain arrangements emerge and understanding the consequences of these arrangements for industry efficiency and competitiveness.

During recent years, new theories on supply management have emerged seeking to solve a wellknown problem within economic theory, i.e. the issue of division of labor and specialization. Each theory, however, has its own specific basis in pursuing solutions to problems concerning how to use and cooperate with suppliers. The reasons for supply management vary, and its conceptual frameworks, which have been used to explain the practice and degree of success obtained, include Transaction Cost Economics (TCE) (Williamson,
1979) and the Core Competence Approach (Prahalad \& Hamel, 1990) among others. TCE represents a general, domain spanning, integrating framework and considerable opportunities for understanding and evaluating many supply management related issues, and has as well the potential to be combined in an interdisciplinary setting with the insights provided by management literature. Williamson (1981) on TCE profoundly altered views on inter-firm exchange. In effect, it has been one of the most influential theories in the study of supply management and makes a valuable contribution to understanding sourcing and predicting the likely success of some supply chain arrangements both in theory and practice, although it alone cannot fully explain the complexities of sourcing (Mclvor, 2009).

\footnotetext{
* Reza Mohammady Garfamy

Faculty of Economics, Management and

Administration Sciences, Semnan University, Iran

E-mail: garfamy@yahoo.com
} 
Moreover, a recent publication by Williamson (2008) points to the need for further elaboration of the link between TCE and supply management, where TCE examines individual transactions, while supply management introduces a broader systems perspective in which groups of related transactions are managed as chains.

Although research interests in supply management are growing, no research has been directed towards a systematic development of its framework. The objective of this study, therefore, is to examine the existing research in an effort to illustrate the possibility of using TCE as a basis for understanding the potential effects of transaction costs on the vertical coordination of a supply chain. We build on existing theoretical perspectives, as well as advance the existing body of literature by proposing a new framework with possibly broader appeal. This paper offers many insights into how supply chains are organized under different governance structures. This study tries to take the approach of developing a typology to illustrate the relationships among concepts and to systematically consider phenomena. The conceptual typology of contractual relations developed herein can help researchers better understand the scope of both the problems and the opportunities associated with supply management.

\section{Literature Review}

\subsection{Supply Management}

A supply chain can be defined as a set of three or more entities (firms or individuals) directly involved in the upstream and downstream flows of products, services, finances and/or information from a source to a customer (Mentzer, DeWitt, Keebler, Min, Nix, Smith, \& Zacharia, 2001). Analytically, a typical supply chain is a network of materials, information and services processing links with the characteristics of supply, transformation and demand (Chen \& Paulraj, 2004). The processes and links under the supply chain umbrella are central to industrial modernity.

The complexity of a supply chain stems from the fact that it is a complex network of chains. Given the potential for countless alternative supply chain configurations, any one firm can be part of numerous supply chains (Mentzer et al., 2001). Each supplier and customer in the supply chain has also many supply chains with its own suppliers and customers. Therefore, a small change in any of the partners' supply chains or even a weak or broken link in the network can create a major reaction in the entire supply chain.

The traditional view of supply management is to leverage the supply chain to achieve the lowest initial purchase prices while assuring supply. Its typical characteristics include multiple suppliers, supplier evaluations based on purchase price, cost-based information bases, arms-length negotiations and formal short-term contracts as well as centralized purchasing. Operating under these conditions encourages fierce competition among suppliers. The fundamental assumption in this environment is that trading partners are interchangeable (Spekman, Kamauff Jr., \& Myhr, 1998) and that they seek advantages based on the survival of the fittest. Under the new paradigm, supply management is redefined as a process for designing, developing, optimizing and managing the internal and external supply components of the supply chain, which is consistent with overall business objectives and strategies. While reduced cost is typically a result, supply management emphasizes leveraging the skills, expertise and capabilities of firms that comprise this competitive network. Supply chain strategy development would be a part of the business unit planning process, which includes efforts aimed at developing and maintaining global information systems, addressing strategic aspects of production or purchasing issues as well as accessing and managing innovation with the purpose of protecting and enhancing core technologies (Prahalad \& Hamel, 1990).

Firms are now pursuing more intensive and interactive relationships with their suppliers, collaborating in operations coordination, developing new products, integrating key business processes, outsourcing non-core processes and sharing cross-functional information on a range of issues (Mclvor, Humphreys, \& McAleer, 1997; Wu, Chiag, Wu, \& Tu, 2004). In fact, firms are striving to develop long-term strategic partnerships with a few competent and innovative suppliers and collaborate with them in joint problem-solving efforts to acquire resources, develop technology, access markets and respond to changing business needs (Mohammady Garfamy, 2009). In essence, supply chain partnering is an arrangement by which separate firms share administrative authority, form social links and accept joint ownership of operating policies. Looser, more openended arrangements replace highly specific, arms-length contracts to remove the firm's boundaries and permit an easier exchange of knowledge. Thus, the traditional pattern of a large, vertically integrated business is being 
replaced by one consisting of complex networks of collaborating firms. This structured approach to the design of a supply chain will result in an organization that is an appropriate mix of the firm's own capabilities with those of suppliers in a relationship that is appropriate to the business strategy.

In this paradigm shift, cooperation is no longer seen as a process between one set of trading partners, but now exists along the entire supply chain (Spekman et al., 1998). Cooperation emphasizes the need to integrate functional silos and views these units as interdependent parts responsible for maximizing the overall effectiveness of the supply chain. What evolves is a network of interrelated firms whose primary objective is to gain strategic advantage for the whole supply chain.

However, some of the implementation issues in supply management are the alignment of partners' business interests, long-term relationship management, reluctance to share information, the complexity of a large scale supply chain, the competence of personnel supporting the supply chain, performance measurement and the incentive systems to support supply management.

\subsection{Transaction Cost Economics}

Unlike Neoclassical Economics, the New Institutional Economics recognizes the costs of using the market mechanism and it terms them transaction costs. Transaction costs are the costs of creating, using, maintaining, changing and governing the organization of economic activity within a vertically integrated firm or in a market. In effect, they are divided into market, managerial and political transaction costs including legal, administrative, information-gathering and other costs associated with negotiating and writing contracts, monitoring performance and enforcing promises. The minimization of absolute or relative transaction costs is not an economically reasonable aim. Rather, what matters for the judgment of the economic quality (efficiency) of an economic entity is its total economic results, and not its level of transaction costs (Furubotn \& Richter, 2000).

TCE uses the concept of transaction costs to explain the organization of firms and the method of their interactions along a supply chain by providing a conceptual framework for investigating some of the organizational challenges and economic risks that firms face. A number of other disciplines including organization theory and contract law have all contributed to the theoretical development of TCE. TCE is also called the markets and hierarchies paradigm, where hierarchies (or firms) replace markets when the price system fails. The choice between markets and hierarchies, as alternative governance mechanisms for completing a set of transactions, depends on the relational efficiency of each. Williamson (1979) outlines the cost-determining attributes (dimensions) of individual transactions as their frequency (the rate of reoccurrence of transactions), the environmental political, social or economic risk surrounding them (environmental and behavioral uncertainty or ambiguity as to transaction definition and performance) and the level of the transferability of assets associated with them (asset specificity). Asset specificity can arise in any of three ways; namely, site specificity (resource immobility), physical asset specificity (technology advantages) and human asset specificity (know-how advantages) (Williamson, 1981). Asset specificity can be non-specific (highly standardized), idiosyncratic (highly customized to the organization) or mixed (incorporating standardized and customized elements in the transaction). In a world where individuals are subject to bounded rationality (neurophysiological, language and judgment limits), opportunistic behavior (cheating, lying and subtle forms of violation of agreements guided by considerations of self-interest with guile), small numbers bargaining (the degree to which a firm has alternative sources of supply to meet its requirements), information impactedness (asymmetrical distribution of information among the exchanging parties) and loss of resource control (outsourcing a product that may be proprietary in nature) as well as the random nature of some events, these characteristics have a major influence on the efficiency of alternative transaction modes (Williamson, 1985).

Governance structures are defined as "discrete structural alternatives that possess distinctive strengths and weaknesses in autonomous and coordinated adaption respects" (Williamson, 2008, p. 15). TCE focuses primarily upon the governance skills or the role of efficient governance through transaction analysis in explaining firms as institutions for organizing economic activity (Mclvor, 2009). For efficient governance, three generic structures emerge: market, hybrid and hierarchy. The three structures differ in governance attributes such as the intensity of the cooperation and coordination mechanisms (or safeguards) (Grover \& Malhotra, 2003). Williamson (1993) argues that TCE deals predominantly 
with dyadic contractual relations. Viewing the firm as a nexus of contracts, the object is to prescribe the best governance structure between firm and its suppliers, customers, workers, etc.

However, there have been criticisms from a conceptual perspective of TCE, whereby some doubts have been raised about the significance and validity of the theory. For instance, Blomqvist, Kyläheiko and Virolainen (2002) mention that classic TCE does not account for the benefits of transactions and neglects the knowledge-based view that also considers evolving capabilities and the knowledge of firms. The other weakness is in applying the idea of human interactions and exchanges as based on the contractual approach so that its most fundamental concept (contractual relations) remains undefined and does not lead to a dynamic perspective. While providing a number of important insights regarding the most efficient means to govern a particular transaction, TCE has been developed and tested under a set of restrictive assumptions that ignore the potential influence that an extant governance form, a firm's existing portfolio of transactions or other firmspecific asset and capability stocks may have on a focal transaction (Leiblein \& Miller, 2003). Furthermore, the empirical work on successful measurement of transaction costs has mostly been treated at the conceptual rather than at the measurement level.

For the purpose of this paper, although there are enormous sources of related literature that have addressed the topics in great depth and breadth over the past years, there is no choice but to ignore a significant majority of the research in the fields and just consider the relevant and available sources in order to address the subject of this study.

\section{Research Method}

A conceptual paper is one in which the objective is to generate and present a theory without verification and empirical adornment, defined as a system of abstract concepts and the relationships between them, with/without presenting a measurement model based on the specific operationalization of those concepts and relationships to stimulate subsequent attempts at verification (Skilton, 2011). On the other hand, since theories that are developed to explain human activities cannot simultaneously be generalizable, accurate and simple, scholars can thereby be content to pursue just one or two when developing theory (Weick, 1979).
In order for an insight to yield a theory, it needs to decompose into concepts and the relationships among them and to integrate these into an elaborated whole. As Kilduff (2006) suggests, the process of theory development requires attending to the activities through which provisional theoretical inputs evolve into a wellorganized whole. In this study, to integrate a wide and diverse body of information about a particular phenomenon, a meta-analysis procedure is used that allows for the examination of trends, patterns and substantial commonalities that may exist in many different studies that have already been conducted. Meta-analysis is a very effective technique for summarizing, comparing and combining as a whole outcomes from several different studies that use the same dependent variable (Salkind, 2006). These conceptual theory development efforts are aimed at helping to close the gap or tensions between what we know and what we need to know about the implications of TCE for supply management.

\section{The Transaction Cost Economics Framework for Supply Management}

Vertical coordination (the governance structure of contractual relations), which is central to the study of supply management, can be viewed as a continuum. At one extreme lie spot markets where products are exchanged between multiple partners, with price as the sole determinant of the final transaction, and where supply management is entirely absent. At the other end of spectrum lies vertical integration where products move between various stages of the supply chain as a result of within-firm managerial orders (Hobbs, 1996). In between the two extremes of polar form lies a myriad of alternative ways of organizing economic activity, which are neither clear market nor clear hierarchy, from strategic alliances, formal written contracts, quasi-vertical integration (joint ventures, franchises and licenses) to tapered-vertical integration, which represent different degrees of vertical coordination.

Over the past few decades, TCE has been the dominant theory for analyzing governance structure choices (Leiblein \& Miller, 2003). TCE argues that one of the determinants of vertical coordination is the nature and level of transaction costs, wherein a change in the transaction costs arising from the exchange of a product may lead to a change in that supply chain (Hobbs, 1996). As infrequency, uncertainty and asset specificity of a 
transaction increase, the choice moves along the spectrum of vertical coordination from spot market towards a more formal type of vertical coordination, where one party has more control over the outcome of transaction, e.g., a strategic alliance, a long-term contract or some form of vertical integration (David \& Han, 2004). The underlying logic of TCE is that firms will favor vertical integration when transaction costs (i.e. adaptation, performance evaluation and safeguarding costs) are greater than internal costs (i.e. production and administration costs).

TCE combines the economic theory with the organization theory to determine the best type of relationship a firm should develop in the marketplace. A firm could have all the activities within its boundary and operate as a hierarchy or it could outsource most of its activities, except for its core competencies, and operate as a virtual corporation, depending on the market for most of its input. There are also hybrid structures in which a firm may outsource only a few activities. Therefore, the hybrid transaction is especially pertinent to the supply chain literature (Williamson, 2008). Firms make decisions on organizational design based on various factors including what investments have to be made specific to the relationship, what activity is critical for effective business performance, uncertainty in the relationship with partners and product complexity. Grover and Malhotra (2003) state that TCE can be used to evaluate how various types of investments within firms can build long-term capabilities and what their impact is on performance. Investments specific to the relationship lock in the supplier and increase the costs of switching to another buyer. The greater the level of asset specificity, the more an alliance partner needs cooperation adaptability in modifying the agreement rather than in leaving the partnership. In the case of a low level of asset specificity, the desire for cooperation adaptability diminishes while the need for exit flexibility is preferred.

It is also difficult to completely eliminate uncertainty because the organization deals with customer orders, which are randomly generated. The demand uncertainty may force a firm to develop a closer relationship with its suppliers to better meet market requirements or alternatively to develop standardized products and have extra inventory to counter the uncertainty (Premkumar, 2000). Similarly, there is uncertainty related to supplies from the suppliers. The supply uncertainty can be due to variations in the lead-time or the quality of the products. Firms also experience uncertainty in their internal subunits, that is, whenever there is a transfer of products or information between subunits, which requires coordination, uncertainty is created. Firms often have twin objectives in managing uncertainty: to reduce their environmental uncertainty by obtaining as much information as possible and to increase information asymmetry to gain maximum benefits from interaction with their partners. However, information asymmetry among participating partners leads to uncertainty, which in turn leads to the inefficiency of the total supply chain (Premkumar, 2000).

A distinguishing feature of the supply chain from traditional vertically integrated firms is that the former is organized on the fundamental premise of synchronization among multiple autonomous entities represented in it. That is, improved coordination within and between various supply chain members is achieved inside the framework of mutually agreed to commitments made by members to each other. The supply chain enforces its common goals and policies on members only to the extent of mutual commitments made to each other. Thus, Pareto-optimality in decisions due to the competing objectives of members may occur. However, decision making at the member level is decentralized. Each member pursues its own goals, objectives and policies conceptually independently of the supply chain, but pragmatically in congruence with supply chain goals. In this respect, a common knowledge base supports the supply chain structure (Chandra \& Kumar, 2000).

Transaction cost economists argue that nonstandard forms of contracting, of which vertical integration is an extreme form, have the purpose and effect of economizing on transaction costs (Williamson, 1985). Considering the hazards of the spot market and contractual incompleteness, transaction costs economists predict that parties will adopt appropriate governance structures from a set of institutional alternatives under a variety of environmental and firm-related factors to prevent ex-post opportunism and thus promote an efficient level of investment. In a supply chain, the contract is a coordination mechanism, which provides incentives to all of its members so that the decentralized supply chain behaves nearly or exactly the same as an integrated one.

Increasingly, successful firms use a higher level of strategic alliance-based global sourcing to address the never-ending battle to reduce costs while maintaining and improving quality and service by cooperating with their suppliers, even when highly specific assets are 


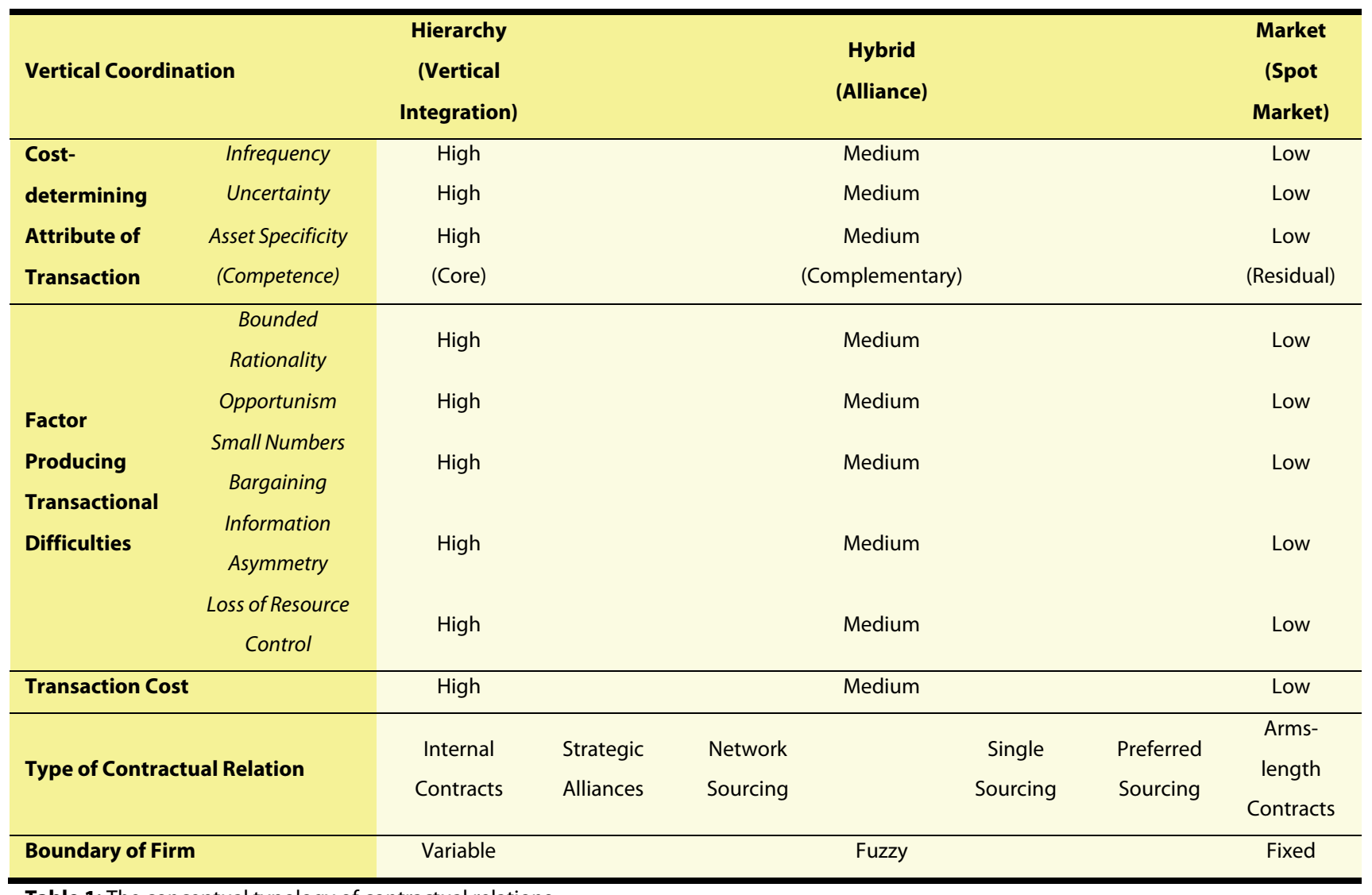

Table 1: The conceptual typology of contractual relations

involved. Murray (2001) argues that this phenomenon is contradictory to the recommendation of TCE in which global internal sourcing (hierarchy) should be used by firms when asset specificity is highly involved. However, it is quite possible for a firm to develop a core competency by integrating the skills of a supplier into a process.

The idea of forming an outsourcing system is meant to establish a dynamic organization through the synergetic combination of dissimilar firms with different core competencies to perform a given business project for achieving a maximum degree of customer satisfaction (Choy \& Lee, 2003). Outsourcing is a form of supply management where the outsourcing firm deliberately rids itself of its assets, infrastructure and people it had used previously or will use in the future to perform the particular process by contracting out or selling some or all of them to a supplier, who in return, provides and manages the services for a certain time and a monetary fee. Outsourcing is thus a specifically defined contractual relationship that is dependent on the supplier meeting the firm's defined performance goals (Razzaque \& Sheng, 1998). An increased level of outsourcing places a premium on the skills needed to identify and distinguish between core and non-core processes, to select and develop suppliers, to structure long-term relationships and to manage suppliers across a range of processes.

The conceptual basis and basic design alternatives for the sourcing decision are based theoretically on TCE, which determines the internal and external boundaries of the firm. The key issue in the sourcing decision is determining the boundaries between two extremes of vertical coordination. Williamson (1985) argues that the decision will always be made in relation to the scope for cost reduction and the importance of asset specificity. Therefore, a firm should outsource activities if to carry them out internally would require excessive investment to get the lowest unit cost. In this respect, hierarchy is directly linked with insourcing and all governance structures with market elements are relevant for the outsourcing design. Thus, as well as assisting in assessing supplier performance, TCE can enhance our understanding of whether it is more appropriate to insource or outsource an activity (Stratman, 2008).

The governance structure decision involves understanding the profitability of an exchange, which can be reached through economizing (reducing transaction costs) or developing completely unforeseen opportunities for exchange (reconfiguring transaction 
costs). It also involves redefining the dimensions of transactions in terms of fitness of purpose in achieving a sustainable position for the supply chain. Core competencies, as defined by their relevance to the sustainability of a margin, can always be controlled through internal contracts. Complementary competencies can be outsourced through close external contracts based on various forms of alliance. And finally, low competencies can be outsourced through armslength contracts. These concepts and the relationships between them are represented in Table 1 by their degree of vertical coordination, which aligns these prototypical governance structures along the market-to-hierarchy continuum.

This table represents the major predictive aspect of TCE with respect to governance structures. A key part of this analytic approach involves undertaking value chain positioning. This refers to the process by which the key decision makers within a firm consciously undertake market positioning through an analysis of the totality of supply and value relationships within their markets, which is achieved through the use of TCE.

In summary, if transaction costs are low due to low levels of cost-determining attributes of a transaction and factors producing transactional difficulties, then market governance will be preferred. Production costs are generally lower in markets due to economies of scale and the scope available to external suppliers, which are subsequently reflected in the market prices. If, on the other hand, transaction costs are high enough to exceed the production cost advantages of the market, then hierarchical governance will be the more appropriate governing structure. Of course, internalization of activities should only take place if the cost reduction exceeds incremental costs due to additional administrative burdens and losses in production efficiencies.

The literature and practice have seen the growth of buyer and supplier relationships from a focus on operational purchasing relationships to strategic partnerships and boundary evaporation based on longterm contracts, mutual support, non-adversarial negotiations and information and risk sharing (Choy \& Lee, 2003). These long-term relationships lead to reduced political, social or economic risks, reduced transaction costs and increased access to economies of scale by bypassing traditional market arrangements to enable a firm to compete with an alternative supply chain. Numerous firms have been downsizing, concentrating on their core competencies, moving away from vertical integration and outsourcing more extensively (Goffin, Szwejczewski, \& New, 1997). The old habits of instigating supplier competition to maintain low prices and dumping suppliers that do not meet expectations are changing, as downsized firms shift more responsibility to their supply bases and recognize the high cost of switching suppliers (Krause \& Ellram, 1997).

TCE can be used to assess different aspects of the quality and richness of the relationships as well as the true value of the developing partnership between interfirm entities. The real productivity, design and quality improvements are not obtainable unless the suppliers in the collaborative relationship innovate to the best of their abilities in conjunction with the firm (Humphreys, Mak, \& Yeung, 1998). The factors, which determine how close the relationships will become, are the degree of mutual dependence, the length of cooperation, the extent of joint projects and technological links as well as the degree of economic satisfaction with the cooperation (Monczka, Callahan, \& Nichols, 1995). Developing relationships, however, takes considerable effort and requires participants to assume a level of trust and reliance in their partners that may reflect a significant departure from established norms. An open and honest environment, key management, coherent and effective internal measurement systems, mutual respect and empathy, commitment to investment as well as financial and commercial arrangements are of particular importance in this aspect (Razzaque \& Sheng, 1998).

Furthermore, TCE focuses on important concerns for operations management scholars, including the development and leveraging of capabilities for competitive advantage, and understanding where it is appropriate to pursue efficiencies and where it is appropriate to pursue collaborative relations with suppliers (Mclvor, 2009). Therefore, the ability of a firm to find a strategic partner to provide the needed supplementary services and maintain the relationship is a source of competitive advantage. It involves the firm attempting to develop and manage a competence-based supplier network and in turn, increases dependence on the supply base and make supply management a key success factor and an organizational imperative (Prahalad \& Hamel, 1990). For some firms, this has meant reducing and streamlining the supplier base so they can better manage relationships with strategic suppliers and for others, it has meant developing cooperative relationships with suppliers. 


\section{Conclusion}

As is obvious from the prior discussion, the major uses and applications of TCE in the supply management field lie in examining inter-firm relationships evident in buyersupplier linkages. Drawing from the New Institutional Economics literature, TCE may be one of the frameworks for testing theories about supply management in order to further our understanding of its intricacies. The economic theory underlying TCE provides an explanation for the existence and structure of firms and for the nature of vertical coordination within a supply chain. Therefore, considerable opportunities exist for evaluating many supply management related issues from this perspective by devising a large number of testable hypotheses and propositions using the theoretical framework of TCE. Although TCE is progressive in terms of mainstream economics literature, and will lead to future research, the insights that it provides on the effect of transaction costs on vertical coordination need to be empirically verified through micro-analytical studies of supply chains (Hobbs, 1996). A convergence of interests is thus suggested for joint research by attempting to provide conceptual and empirical facilitation for future research.

By examining the existing research in an effort to illustrate the possibility of using TCE as a basis for understanding the potential effects of transaction costs on the vertical coordination of a supply chain, a conceptual typology of contractual relations is developed that can have a broader appeal and can help researchers better understand the scope of both the problems and the opportunities associated with supply management.

Concerning the debate between theoretical rigor and managerial practice, the implementation of supply management is a cultural change in any firm and needs dedicated efforts from upper management (Huang, Uppal, \& Shi, 2002). Strategic issues involve understanding the dynamics of the supply chain, development of objectives for the whole supply chain and development of relations with business partners. The strategic aspect also includes the research determination of opportunities, which can enhance the competitiveness of a firm as a part of the supply chain or network of supply chains.

Several research avenues can be outlined with the application of the rich lens of TCE to lower overall transaction costs in sourcing, allocation of investments as well as supply chain coordination, integration and distribution (Grover \& Malhotra, 2003). To present a meaningful discussion of the testability and/or extension of the theory, the presented conceptual typology can be tested as a whole by considering all of its elements and can be extended by integrating other aspects of TCE in its content. As a research limitation, however, researchers dealing with supply management should augment the conceptual typology by integrating further parameters, such as risk preferences, trust propensity, sourcing strategy or market environment, into their calculus and combining it with other factors influencing the outcome of supply arrangements. ⿷匚

\section{Acknowledgements}

The reviewers' constructive and helpful comments towards improving the quality of the paper are acknowledged.

\section{References}

Blomqvist, K., Kyläheiko, K., \& Virolainen, V.M. (2002). Filling a gap in traditional transaction cost economics: Towards transaction benefitsbased analysis. International Journal of Production Economics, 79 (1), 1-14.

Chandra, C., \& Kumar, S. (2000). An application of a system analysis methodology to manage logistics in a textile supply chain. Supply Chain Management: An International Journal, 5 (5), 234-245.

Chen, I.J., \& Paulraj, A. (2004). Towards a theory of supply chain management: the constructs and measurements. Journal of Operations Management, 22 (2), 119-150.

Choy, K.L., \& Lee, W.B. (2003). A generic supplier management tool for outsourcing manufacturing. Supply Chain Management: An International Journal, 8 (2), 140-154.

David, R.J., \& Han, S. (2004). A systematic assessment of the empirical support for transaction cost economics. Strategic Management Journal, 25 (1), 39-58.

Furubotn, E.G., \& Richter, R. (2000). Institutions and Economic Theory: The Contribution of the New Institutional Economics. Ann Arbor: The University of Michigan Press.

Goffin, K., Szwejczewski, M., \& New, C. (1997). Managing suppliers: when fewer can mean more. International Journal of Physical Distribution \& Logistics Management, 27 (7), 422-435.

Grover, V., \& Malhotra, M.K. (2003). Transaction cost framework in operations and supply chain management research: theory and measurement. Journal of Operations Management, 21 (4), 457-473.

Hobbs, J.E. (1996). A transaction cost approach to supply chain management. Supply Chain Management: An International Journal, 1 (2), 15-27.

Huang, S.H., Uppal, M., \& Shi, J. (2002). A product driven approach to manufacturing supply chain selection. Supply Chain Management: An International Journal, 7 (4), 189-199.

Humphreys, P., Mak, K.L., \& Yeung, C.M. (1998). A just-in-time evaluation strategy for international procurement. Supply Chain Management: An International Journal, 3 (4), 175-186. 
Kilduff, M. (2006). Editor's Comments: Publishing Theory. Academy of Management Review, 312, 252-255.

Krause, D.R., \& Ellram, L.M. (1997). Success factors in supplier development. International Journal of Physical Distribution \& Logistics Management, 27 (1), 39-52.

Leiblein, M.J., \& Miller, D.J. (2003). An empirical examination of transaction- and firm-level influences on the vertical boundaries of the firm. Strategic Management Journal, 24 (9), 839-859.

Mclvor, R. (2009). How the transaction cost and resource-based theories of the firm inform outsourcing evaluation. Journal of Operations Management, 27 (1), 45-63.

Mclvor, R., Humphreys, P., \& McAleer, W. (1997). The implications of the trend towards partnership sourcing on buyer-supplier relations. Journal of General Management, 23 (1), 53-70.

Mentzer, J.T., DeWitt, W., Keebler, J.S., Min, S., Nix, N.W., Smith, C.D., \& Zacharia, Z.G. (2001). DEFINING SUPPLY CHAIN MANAGEMENT. Journal of Business Logistics, 22 (2), 1-25.

Mohammady Garfamy, R. (2009). Supplier selection and business process improvement. International Journal of Services and Operations Management, 5 (2), 233-250.

Monczka, R.M., Callahan, T.J., \& Nichols, E.L. (1995). Predictors of relationships among buying and supplying firms. International Journal of Physical Distribution \& Logistics Management, 25 (10), 45-59.

Murray, J.Y. (2001). Strategic alliance-based global sourcing strategy for competitive advantage: A conceptual framework and research propositions. Journal of International Marketing, 9 (4), 30-58.

Prahalad, C.K., \& Hamel, G. (1990). The Core Competence of the Corporation. Harvard Business Review, 68 (3), 79-91.

Premkumar, G.P. (2000). Interorganization systems and supply chain management: An information processing perspective. Information Systems Management, 17 (3), 56-69.

Razzaque, M.A., \& Sheng, C.C. (1998). Outsourcing of logistics functions: a literature survey. International Journal of Physical Distribution \& Logistics Management, 28 (2), 89-107.

Salkind, N.J. (2006). Exploring Research (6th ed.). Upper Saddle River: Pearson Education.

Skilton, P.F. (2011). Getting the reader to "I get it!": clarification, differentiation and illustration. Journal of Supply Chain Management, 47 (2), 22-28.

Spekman, R.E., Kamauff Jr., J.W., \& Myhr, N. (1998). An empirical investigation into supply chain management: a perspective on partnerships. Supply Chain Management: An International Journal, 3 (2), 53-67.

Stratman, J.K. (2008). Facilitating offshoring with enterprise technologies: reducing operational friction in the governance and production of services. Journal of Operations Management, 26 (2), 275287.

Weick, K.E. (1979). The Social Psychology of Organizing (2nd ed.). Reading: Addison-Wesley.

Williamson, O.E. (1979). Transaction-Cost Economics: The Governance of Contractual Relations. Journal of Law and Economics, 22 (2), 233-261.

Williamson, O.E. (1981). The Economics of Organization: The Transaction Cost Approach. American Journal of Sociology, 87 (3), 548577.

Williamson, O.E. (1985). The Economic Institutions of Capitalism. New York: The Free Press.

Williamson, O.E. (1993). Transaction Cost Economics and Organization Theory. Industrial and Corporate Change, 2 (2), 107-156.
Williamson, O.E. (2008). Outsourcing: transaction cost economics and supply chain management. Journal of Supply Chain Management, 44 (2), 5-16.

Wu, W., Chiag, C., Wu, Y., \& Tu, H. (2004). The influencing factors of commitment and business integration on supply chain management. Industrial Management \& Data Systems, 104 (4), 322-333. 